\title{
Numerical Evaluation of the Coal Metamorphism Thermodynamics Equation (CMTE)
}

\author{
Ma Qinghua ${ }^{1,}$,, Zhang Xuemei ${ }^{1}$, Li Dong ${ }^{1}$, Hao Jingyuan ${ }^{1,2}$ \\ ${ }^{1}$ Energy \& Chemical Engineering Research Center, Xi'an Siyuan University, Xi'an, China \\ ${ }^{2}$ College of Chemical Engineering, Xi'an Jiaotong University, Xi'an, China \\ Email address: \\ 854042134@qq.com (Ma Qinghua),476333285@qq.com (Zhang Xuemei), zuizuixuan123@163.com (Li Dong), \\ 923716217@qq.com (Hao Jingyuan) \\ *Corresponding author
}

\section{To cite this article:}

Ma Qinghua, Zhang Xuemei, Li Dong, Hao Jingyuan. Numerical Evaluation of the Coal Metamorphism Thermodynamics Equation (CMTE). International Journal of Economy, Energy and Environment. Vol. 6, No. 5, 2021, pp. 110-113. doi: 10.11648/j.ijeee.20210605.15

Received: September 3, 2021; Accepted: October 15, 2021; Published: October 19, 2021

\begin{abstract}
In order to quantitatively study the metamorphism of coal, by calculating the changes of reflectivity with time and temperature and the changes of temperature with time and reflectivity, the results show that the temperature time reflectivity ternary coal metamorphism thermodynamic equation (Cmte) proposed by $\mathrm{Mr}$. Wu Chonglong is feasible. Although it is only an empirical formula, the mathematical formula is more convenient and accurate than the diagram, The critical temperature of lignite is $49.3^{\circ} \mathrm{C}$ and that of long flame coal is $56.9^{\circ} \mathrm{C}$. The empirical formula of temperature time reflectance is demonstrated to explain the metamorphism of coal. By compiling temperature reflection (time) maps of middle coal formation in Carboniferous, Jurassic and Cretaceous, this paper explains the concept of "the longer the thermal time, the higher the degree of metamorphism" with isothermal horizontal line or equal reflection vertical line. The temperature and effective metamorphic time in the literature of Nantong coalfield in Sichuan further prove the accuracy and practicability of Cmte. The mathematical formula of temperature time reflectance can not only know the cross verification temperature of time and reflectance, but also know the time with a difference of less than $1.4 \%$ from the original effective metamorphic time. It is proved that the empirical formula of temperature time reflectance can explain the metamorphism of coal.
\end{abstract}

Keywords: Coal Metamorphism Thermodynamics Equation, Temperature-time-reflectivity, Long Flame Coal

\section{Introduction}

The theoretical study of coal metamorphism not only helps to correctly explain the geological structure of an area, but also provides a basis for coal quality prediction, rational development and oil and gas exploration. Whether the normal temperature in the deep is a heat source, magmatic heat directly enters the coal seam, or thermal metamorphism with shear force is related to temperature and actual thermal time, so metamorphic temperature and metamorphic time are two important variables of coal metamorphism $[1,2]$.

Vitrinite reflectance of coal is not only a representative parameter to measure the degree of coal metamorphism, but also an important variable. The article [3-6] represented by "Yangqi coal metamorphism theory" scientifically and systematically describes the types, phenomena and characteristics of coal metamorphism. Based on the general principle of thermodynamics and referring to the Bostick curve of Chinese boundary data, a three variable empirical formula of temperature time reflectivity is established by binary regression [3]. However, few domestic and foreign coal technology experts and scholars have made a systematic analysis on the quantitative research of coal metamorphism. Which mathematical equation can be used for the study of quantitative coal metamorphism. Therefore, this paper intends to make some attempts and Research on the above problems.

\section{Ternary Equation}

HOOD proposed ternary plot [7] representing temperature -time-reflectivity in 1975. BOSTICK in 1979 [8] indicates temperature-time-reflectivity, according to the exploration data of the Los Angeles Basin and Ventura Basin. Wu Chong 
Long proposed the formula [3] for temperature-timereflectivity in 1997 as following:

$$
\ln (T-273)=\frac{646.32}{\ln t+111.85}-\frac{0.492 t^{0.093}}{R_{0}}
$$

Where

t: "absolute age" or "effective heat time", million years;

R0: reflectivity, \%;

$\mathrm{T}$ : temperature, $\mathrm{K}$.

\section{Results and Discussions}

\subsection{Temperature-time- Reflectivity Ternary Equation}

From the perspective of science, the temperature-timereflectivity ternary equation is more realistic and perfect than any other binary equations, such as temperature - parameter (reflectivity, mirror coal paramagnetic resonance, or calculus color change index).

Furthermore, the national standard method of measuring reflectivity is been set and followed [9]. Therefore, there should not any discrepancy for the reflectivity measurement.

For the relationship between Chinese soot reflectivity and coal species (gas coal, fat coal, coking coal, lean coal, poor coal, weak sticky coal, non-adhesive coal and coal to long flame coal) we can refer to an article [10].

Degree of coalification through reflectivity can be referred to industry standard [11].

There are three geological periods that produce from low order coal (long flame coal) to higher order coal (anthracite). They are:

(1) Carboniferous: about 320 million to 278 million years ago. Chinese Carboniferous coal was basically distributed in the Yellow River basin. Carboniferous coal species range from long flame coal to anthracite.

(2) Jurassic: about 205 million to 159 million years ago. Jurassic coal was mainly concentrated in the border zone of Inner Mongolia, Shaanxi, Gansu, Ningxia and northern Xinjiang. The Jurassic coal species range from lignite to anthracite.

(3) Cretaceous: about 142 million-99 million years ago. Cretaceous coal was distributed in eastern Inner Mongolia and the three northeastern provinces of China. Cretaceous coal from the three northeastern provinces ranges from long flame coal to anthracite.

Since the reflectivity and coal forming periods are known, the temperature is the only variable, which needs to be investigated with uncertainty. Then obtaining the controversial dependent variables with two undisputed independent variables just shows the theoretical science and mathematical applicability of the ternary equation.

\subsection{Verification of CMTE}

There are some examples, which have two firmly believed data, but with a qualitative conclusion. CMTE can be used to verify the conclusions with quantitative guarantee.

Example 1: Because the Moscow Basin peat formed by the
Early Carboniferous Period (350 million years) has never settled to a depth of temperature higher than $25^{\circ} \mathrm{C}$, it is still in the woody lignite stage [12]. This example is for $\mathrm{t}=350$; $\mathrm{T}=298 \mathrm{~K}$. The calculated reflectivity, $\mathrm{R}_{0}=0.373 \%<0.5 \%$, belongs to lignite.

Example 2: On the Louisiana coast of USA, the ground temperature of Central and Upper Miocene (about 17 million years) is about $140^{\circ} \mathrm{C}$, producing high volatile [12] coal. This example is for $\mathrm{t}=17 ; \mathrm{T}=438 \mathrm{~K}$. Calculated $\mathrm{R}_{0}=1.21 \%$, belongs to fat coal. The volatility of fat coal is about $\mathrm{Vdaf}=25 \%$ [8], belongs to high volatile coal.

Example 3: Low volatile bituminous coal [12] under the same $140^{\circ} \mathrm{Cground}$ temperature conditions were found in northern Germany. This example is for $\mathrm{t}=270$; $\mathrm{T}=438 \mathrm{~K}$. $\mathrm{R}_{0}=2.09 \%$, lean coal. The volatile $\mathrm{V}_{\mathrm{daf}}=$ of lean coal is about $13 \%$ [10], belongs to low volatile coal.

Example 4: If the heat time of coal is long enough (more than 100 million years), the temperature of $150^{\circ} \mathrm{C} \sim 200^{\circ} \mathrm{C}$ can form anthracite [13]. This example is the $\mathrm{t}=100$; the $\mathrm{T}=473 \mathrm{~K}$. $\mathrm{R}_{0}=3.00 \%$, belongs to high coal grade I [11], the lowest grade anthracite.

Example 5: Carboniferous (350 million) Permian (287 million) period coal at its ground temperature is more than $50^{\circ} \mathrm{C}$, the coal quality is slowly and gradually improved to coking coal and lean coal [13]. The vitrinite reflectance of coking coal is $1.13 \%<$ Rcoking coal $<1.66 \%$ [15]. The reflectivity of lean coal is $1.40 \%<\mathrm{R}$ thin coal $<1.82 \%$ [10]. This is the corresponding four temperatures for two geological ages. It is easy to calculated:

1. In the Carboniferous, to reach coking coal, the TW could be reached $114.3^{\circ} \mathrm{C}>50^{\circ} \mathrm{C}$.

2. In the Carboniferous, to reach lean coal, the TW could be reached reached $132.1^{\circ} \mathrm{C}>50^{\circ} \mathrm{C}$.

3. In the Permian, to reach coking coal, the TW could be reached reached $117^{\circ} \mathrm{C}>50^{\circ} \mathrm{C}$.

4. In the Permian, to reach lean coal, the TW could be reached reached $134.9^{\circ} \mathrm{C}>50^{\circ} \mathrm{C}$.

\subsection{Verify Some the Critical Temperatures}

There are few obscure conscription regarding the critical temperature for several grade of coal in coal chemistry. The critical temperature is the lowest temperature required for coal to rise from lower to higher grades. How to prove that the critical temperature of coal metamorphism is roughly defined as: lignite: $40 \sim 50^{\circ} \mathrm{C}$, long flame coal: $<100^{\circ} \mathrm{C}$, typical bituminous coal: $<200^{\circ} \mathrm{C}$, anthracite: $<350^{\circ} \mathrm{C}$. CMTE has been used to calculate the critical temperature.

For lignite: Time Selection Early Jurassic (205 million years), lignite $\mathrm{R}_{0}=0.50 \%$. A calculated temperature of $49.3^{\circ} \mathrm{C}$ meets the lignite critical temperature of $40 \sim 50^{\circ} \mathrm{C}$.

For flame coal: the late Carboniferous (320 million years). The reflectivity of long flame coal is between $0.51 \%$ to $0.64 \%$ [15]. The value of $\mathrm{R}_{0}=$ was $0.58 \%$, calculated at a calculated temperature of $56.9^{\circ} \mathrm{C}$, consistent with the critical temperature of $<100^{\circ} \mathrm{C}$.

For the typical bituminous coal time, choose the late Paleozoic Carboniferous, about 320 million years ago. Typical 
vitrinite reflectance of bituminous coal is between [15], $0.75 \%$ to $2.50 \%$. The $\mathrm{R}_{0}=$ was taken at $1.625 \%$, at a calculated temperature of $144.9^{\circ} \mathrm{C}$, meeting the critical temperature of the typical bituminous coal, $<200^{\circ} \mathrm{C}$.

For anthracite time was selected about 320 million years ago in the late Paleozoic Carboniferous anthracite. Typical vitrinite reflectance of Anthracite is between $2.51 \%$ to $6.0 \%$ [15]. The $\mathrm{R}_{0}=$ was taken at $4.26 \%$, at a calculated temperature of $199.7^{\circ} \mathrm{C}$. The $\mathrm{R}_{0}=$ was taken at $6.0 \%$, and the calculated temperature was $212^{\circ} \mathrm{C}$, meeting the critical temperature of anthracite at $<350^{\circ} \mathrm{C}$.

\subsection{Illustrate Temperature and Time Relation}

How to verify and show that under roughly the same temperature, the longer the heat time, the higher the metamorphic degree?

The late Carboniferous to early Permian, about 320-278 million years, early 205-159 million Jurassic, and early Cretaceous, about 142-99 million years, are three coal forming periods from long flame to anthracite. Taken the reflectivity between $0.65 \%$ to $0.90 \%$ as the example to illustrate how to answer the above question. The reflectivity is divided into 42 equal segments, namely $(0.9 \%-0.65 \%) /$ $42=0.006 \%$, as the increment of the reflectivity, and the corresponding time increment is one million years. Therefore, a temperature-reflectivity figure corresponding three coal forming period can be created as Figure 1. The longitudinal axis of Figure 1 indicates the temperature. The horizontal axis is the reflectivity, and also represents the time increment.

Carboniferous line, the starting reflectivity is $0.65 \%$, and the corresponding starting time is 278 million years. When the reflectivity is $0.71 \%$, the reflectivity increment of $0.06 \%$ is equivalent to the time increment of 10 million years, and the corresponding time is 288 million years.

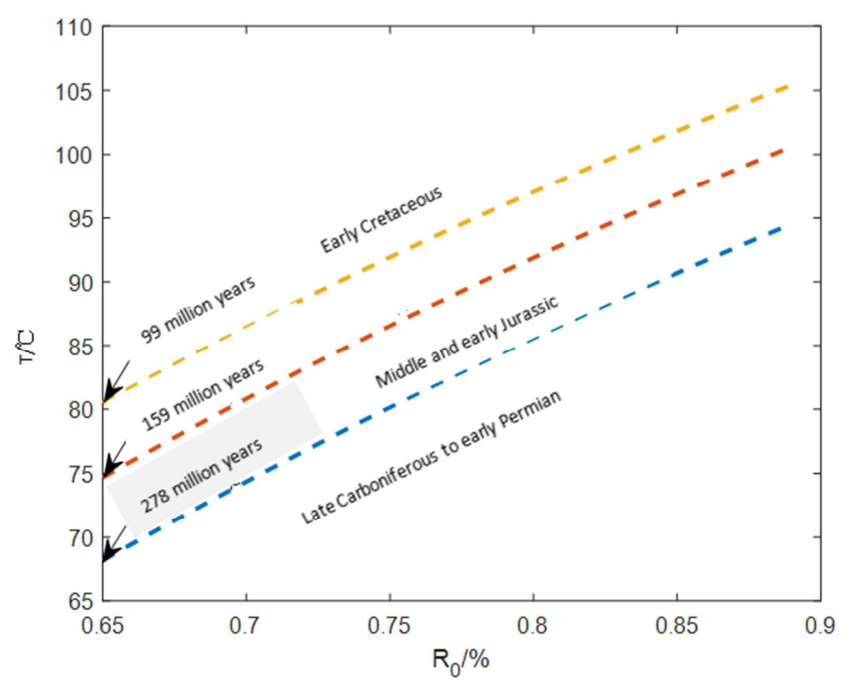

Figure 1. Temperature reflectance curve of medium grade coal II in three coal forming periods.

A horizontal line is drawn at $90^{\circ} \mathrm{C}$, which will crossed the Cretaceous coal forming period line at reflectivity of $0.73 \%$, and roughly equivalent to 113 million years; which then will crossed the Jurassic coal forming period line at reflectivity of $0.78 \%$, and roughly equivalent to 181 million years; which finally will crossed the Carboniferous coal forming period line at reflectivity of $0.85 \%$, and roughly equivalent to 311 million years. This clearly proves that "the longer time the heat occurs, the higher the metamorphism at the same temperature" [13].

A vertical line is drawn at $\mathrm{R}_{0}=0.75 \%$, which will cross the Carboniferous line at temperatures of $80.4^{\circ} \mathrm{C}$, and roughly equivalent to 295 million years; which then will crossed the Jurassic coal forming period line at the temperature of $86.8^{\circ} \mathrm{C}$ and roughly equivalent to 176 million years; which finally will crossed the Cretaceous coal forming period line at the temperature of $92.1^{\circ} \mathrm{Cand}$ roughly equivalent to 116 million years. This vertical line illustrates that "the same metamorphism degree can be reached at both longer time with lower temperature or shorter time with higher temperatures" [13].

\subsection{Comparison with the Paleogeothermal Field Temperature}

Finally, equation (1) is also used to verify the results of other literature calculations. In the paleogeothermal field temperature research literature of the coal field in Nantong, Sichuan Province [14, 15], Tan Yongjie used the effective metamorphic age of 40 million years according to the geological data of Cretaceous Yanshan Formation. Since the Cretaceous Yanshan Formation has an absolute age of 99 million years, which is much older than 40 million years. Tan Yongjie did not mention how to calculate the effective metamorphic age of 40 million years, in stead, just through the result. In the original article, the temperature measurement of "Yutianpu Maokou-Longtan Group"'s secondary and primary package was $180 \sim 190^{\circ} \mathrm{Cand}$ the vitrinite reflectance of "Yutianpu" $\mathrm{R}_{0}=2.5 \sim 2.6 \%$. If the arithmetic mean of temperature as $185^{\circ} \mathrm{C}$ and the arithmetic mean of reflectivity as $\mathrm{R}_{0}=2.55 \%$ are the two known variables in Equation (1), the effective metamorphic age can be calculated. The result is 39.45 million years, which has only $<1.4 \%$ error from the Tan Yongjie's original value.

\section{Conclusions}

(1) Although the temperature-time-reflectivity three-variable mathematical formula is just an empirical formula, the mathematical formula is more convenient and accurate than the illustration, and more in line with the coal metamorphism scientific principles.

(2) Demonstrates that the temperature-time-reflectivity empirical formula explains coal metamorphism by four examples of knowing time and temperature and calculating a lignite critical temperature of $49.3^{\circ} \mathrm{Cand}$ long flame coal critical temperature of $56.9^{\circ} \mathrm{C}$.

(3) An innovated method of applying the reflectivity increment and time increment coupling shows that "the longer the heat time, the higher the coal-chemical degree" with the temperature horizontal line, and the reflectivity vertical line that "coal can achieve the same 
degree of deterioration by the long time low temperature or the short time high temperature".

(4) The temperature-time-reflectivity mathematical formula can know both the time and reflectivity cross-validation temperature, but also the time, which is $<1.4 \%$ different from the original effective metamorphic time.

\section{Fund Project}

General Special Scientific Research Plan of Education Bureau in 2020, Shaanxi Province (20JK0858).

\section{Acknowledgements}

Thank you for your valuable comments and suggestions on my article. Your professionalism and patience will be a powerful help on my way to success. Thank you again!

\section{References}

[1] Coal degree classification of vitrinite reflectance. Coal industry standards. MT/T 1158-2011.

[2] Chen Qingru, Liu jiongtian. China clean coal [M]. Xuzhou, China University of mining and Technology Press, 2009.

[3] Wu Chonglong, Yang Qi, Liu Gang, et. al., Principles and methods of thermodynamics for analysis of coal metamorphism [J]. Journal of China Coal Society, 1997, 22 (3): 225-229.

[4] Yang Qi. A study on coal metamorphism in China [J]. Earth Science-Journal of China University of Geosciences, 1989, 14 (4): $341-345$.

[5] Yang Qi. Superimposed metamorphism of Chinese coal [J].
Earth Science-Journal of China University of Geosciences, 1999, 6 (z1): 1-8.

[6] Yang Qi, Wu Chonglong, Tang Dazhen, et al. Coal metamorphism in China [J]. Earth Science-Journal of China University of Geosciences, 1996, 21 (3): 311-319.

[7] Hood A, Gutjahr C C M, Heacock R H. Organic metamorphism and the generation of petroleum [J]. Bull. AAPG, 1975, 59 (6): 986-996.

[8] Bostick N H, Cashman S M, McCulloh T H, et al. Gradients of vitrinite reflectance and present temperature in the Los Angeles and Ventura Basins, California. In: Oltz D F, ed. Low temperature metamorphism of kerogen and clay minerals. Los Angeles: Pacific Section, SEPM (Society for Sedimentary Geology), 1979, 65-96.

[9] Method of determining microscopically the reflectance of vitrinite in coal. GB/T 6948-2008.

[10] Li Wenhua, Bai Xiangfei, Yang Jinhe, et al. Correspondence between mean maximum reflectance of Vitrinite and classification of bituminous coals [J]. Journal of China Coal Society, 2006, 31 (3): 342-345.

[11] Classification of coalification degree by vitrinite reflectance. MT/T 1158-2011.

[12] Hu Zhongya. Analysis of the effects of temperature, time and pressure on metamorphism [J]. Silicon Valley, 2010, (08): 4.

[13] Zhang Shuangquan. Coal chemistry [M]. China University of Mining and Technology Press. 2015.

[14] Tan Yongjie. A study on the paleogeothermal field temperature recovery method of coal metamorphism [J]. Coal Geology \& Exploration, 1989, (2): 30-36.

[15] Huang Kexing, Tan Yongjie. Paleogeothermal field of coal metamorphism in Nantong coalfield Sichuan province [J]. Journal of China Coal Society, 1990, 15 (4): 54-62. 